\title{
INVESTIGATION INTO THE UV-PROTECTION OF WOVEN FABRICS COMPOSED OF METALLIC WEFT YARNS
}

\author{
Mohammad Ghane*, Ehsan Ghorbani \\ Department of Textile Engineering, Isfahan University of Technology, Isfahan, 84156-83111, Iran \\ ${ }^{*}$ Corresponding author: m-ghane@cc.iut.ac.ir
}

\begin{abstract}
:
The destructive effects of sun UV radiation on human skins are now very clear to everyone. Most of the present studies were focused on the fabrics' structural parameters such as density, warp and weft yarns finenesses, fabric pattern and printing or finishing treatments applied to the fabrics. The aim of this work is achieving a technique through which the produced fabrics possess a higher UV-protection ability. For this purpose, two different metals including aluminium and copper yarns were employed in fabrics production process and their effects on UV-protection ability of the produced fabrics were investigated. Six different fabric samples comprised of either cotton/polyester, nylon yarns as the warp yarns as well as either aluminium or copper yarns as the weft yarns were produced. Using the spectrophotometer technique, which is known as one of the UPF measuring method, the absorbency and reflectivity of fabrics within the specified range of electromagnetic waves (specially the UV radiation) were determined. The results illustrated that the higher UV absorbency was related to the fabric possessing the copper yarns in their structures. It was concluded that the absorption ability of nylon fabrics is higher than that of the cotton/polyester samples.
\end{abstract}

Keywords:

Woven fabric, Metallic yarns, UV protection, radiation energy, spectral irradiance, spectrophotometer,

\section{INTRODUCTION}

Among the variety of radiations, ultraviolet sun rays (UV) allocated the highest radiant energy. UVAand UVB with 320-340 $\mathrm{nm}$ and 280-320 nm wavelengths, respectively, are classified as subsets of this kind of radiation which have some destructive effects on human skins such as cancroids, premature skin aging, rashes and even the skin sunburn. Nowadays, these problems are being prevalent due to the gradual destruction of ozone layer which is known as an atmosphere protective layer against the UV radiation. The results of studies indicate that decreasing 2 to 5 per cent of ozone concentration leads to increasing the skin cancer disease. In addition to ozone destruction, the Environment Security Agency of America has estimated almost 3 to 15 million cases of skin cancer disease for year 2075, which is mainly due to the changes of human lifestyles and too much exposure into the sun radiation [1].

In the recent decades, lots of tries were held by different researchers in order to decrease the exposure of UV radiations. Producing the sun glasses, protective hats and some other equipment based on textile structure are the results of researchers' studies. Generally, the UV protection ability of textile products depends on different factors including fibres type, weave pattern, colour, treatment operation, additive materials and also the washing procedure. In some other researches, the main protective parameters of fabrics are enumerated as fibres type, fabric structure, specific porosity, fabric thickness and areal density, moisture content, and some finishing treatments such as dying, fluorescence materials of bleaching, UV absorptive materials and other chemical treatments [2]. Butola and Joshi studied the photo stability of HDPE filaments stabilized with UV absorbers (UVA) [3]. They assessed the UV protective ability of the HDPE films by measuring Ultra Violet Protection Factor (UPF). They concluded that UV absorbers improve the stability of the filaments significantly. Chowdhury et al investigated on the effect of UV radiant on the photochromic properties of some colorants in textile applications [4].

In general, a fabric is comprised of fibres which could absorb, reflect or scatter the emitted radiation. As a result of these phenomena, the sun radiant energy would be prevented to meet the skin. The fabric behaviour in associated with the sunbeam radiation on its surface is illustrated in Figure 1.

In numerous studies, it has been demonstrated that fibre types and textile processes have significant effect on UV protection [5, 6, 7, 8]. Saravanan [9] performed a survey on the effective parameters of textile materials on the UV protection performance of textile materials. Saravanan concluded that the best technique for reducing UV exposure is to avoid sun exposure, but this is an unacceptable solution to all. Recreational exposure accounts for most of the significant UVR exposures of the population, and occupational exposure is significant. Farouk et al. [10] reported the synthesis and characterization of nanosized zinc oxide particles to improve the UV absorption of fabric. They modified sol-gel-based inorganic-organic hybrid polymers with these particles and applied to cellulosic cotton $(100 \%)$ and cotton/polyester (65/35\%) fabrics. 


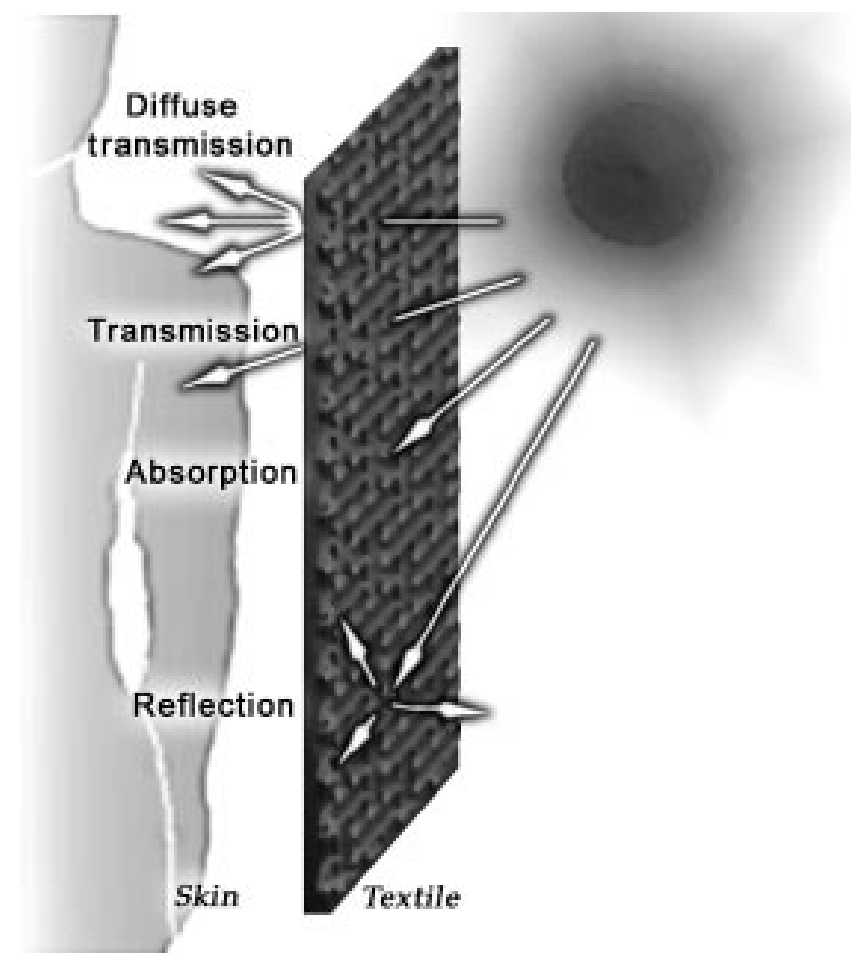

Figure 1. Fabric behaviour against the sun beam radiation [2]

For this reason, considering the history of fibre production process would be known as an essential point in order to conduct such an accurate investigation. In other literatures [11], considering the composition of fibre-dying-finishing has been emphasized more than the fibres only.

According to the investigations performed on 30 different kinds of commercial textiles by Gambishler et al [12], it was observed that the bleached cotton, linen, and viscous-rayon fibres have low protection ability against the UV radiation. Studies of Curiskis and Piltrope [13] also declared the same result. They stated that the bleached cotton would probably be more affected against the UV radiation due to the elimination of natural pigments during the bleaching process. Algaba et al [14] found that the lack of UV-protection ability of fabrics produced from bleached cotton yarns wouldn't be compensated by increasing the fabric density. Crews et al [15] demonstrated that the bleaching operation could significantly increase the UV transmission ability of fabrics. As an example, they concluded that UV radiation transmission ability of bleached silky fabrics is 4 times higher than that of the non-bleached sample. Reinert et al investigated the woollen fabrics UPF factor though their researches. They have demonstrated that the pores within the wool fibre structure would significantly increase the fibre protection ability. Thereafter, Davis et al investigated the UV protection of fabrics produced from different kinds of fibres by considering the same structure and weight. They concluded that UV-resistance of nylon, acrylic and acetate fibres is relatively low and consequently these structures could be classified in poor protection group [16-19].

Gies et al. [20] studied the ultraviolet radiation protection by clothing. They detailed a comparison of UPFs derived from the in vitro tests for 16 fabric samples against in vivoSPF tests.
They concluded that the agreement between the two sets of results was very good. Dimitrovski et al [21] evaluated the structure of monofilament PET woven fabrics and their UV protection properties and presented a mathematical model. They argued that mathematical model enables the calculation of the UPF values of woven fabrics by which adequate UV protection properties could be achieved.

\section{Experiment}

\subsection{Sample preparation}

Before preparing the fabric samples, it should be considered that the metallic yarns don't have a sufficient strength in order to be wrapped on the beam. Thus, they were sued as weft. The diameter of copper and aluminium yarns was 200 micrometres. The warp yarns consist of cotton/polyester and nylon. The specifications of cotton/polyester and nylon yarns used in this research are given in Table 1.

Table 1. Yarns specifications used in fabric structures

\begin{tabular}{|c|c|c|}
\hline Yarn type & Cotton/polyester & Nylon6 \\
\hline Blend ratio & $40: 60$ & 100 \\
\hline Yarn count & $20 \mathrm{Ne}$ & 300 Den \\
\hline $\begin{array}{c}\text { Multiply/ } \\
\text { multifilament }\end{array}$ & Single ply & 6 filaments \\
\hline
\end{tabular}

Along with adding the metal component within the fabric structures, two essential points must be considered: the first point is the metal type selection and the second one relates to the question whether the metallic yarns could be used as warp and weft of fabrics or not. Because of the abundance and low cost of copper as well as the low density of aluminium compared to the other metals, these two kinds of metal were used in fabric samples production. Detailed information about the copper and aluminium metals used in this work are given in Tables 2 and 3, respectively.

Table 2. Copper specifications, Commercial Code 22000

\begin{tabular}{|c|c|c|c|c|c|}
\hline \multicolumn{5}{|c|}{ Component (\%) } \\
\hline $\mathbf{C u}$ & $\mathbf{F e}$ & $\mathbf{P b}$ & $\mathbf{N i}$ & $\mathbf{Z n}$ & Others \\
\hline $88-91$ & 0.1 & 0.3 & 0.5 & $7.9-10.9$ & 0.2 \\
\hline
\end{tabular}

Table 3. Aluminium specifications, Commercial Code 1100

\begin{tabular}{|c|c|c|c|c|c|c|c|}
\hline \multicolumn{7}{|c|}{ Component (\%) } \\
\hline Al & $\mathbf{B e}$ & $\mathbf{S i}$ & $\mathbf{F e}$ & $\mathbf{C u}$ & $\mathbf{M n}$ & $\mathbf{Z n}$ & others \\
\hline 98 & 0.0008 & 0.95 & 0.1 & $0.05-0.2$ & 0.05 & 0.1 & 0.15 \\
\hline
\end{tabular}

In total, six types of fabrics were produced. The wave pattern for all fabric samples was plain wave. The warp and weft density were identical for all fabric samples and were set to be 16 threads per centimetre. The characteristics of the produced samples are given in Table 4. 
Table 4. The characteristics of woven fabric samples

\begin{tabular}{|c|c|c|c|}
\hline $\begin{array}{c}\text { Fabric } \\
\text { sample }\end{array}$ & $\begin{array}{c}\text { Weave } \\
\text { pattern }\end{array}$ & $\begin{array}{c}\text { Warp } \\
\text { yarn }\end{array}$ & $\begin{array}{c}\text { Weft } \\
\text { yarn }\end{array}$ \\
\hline Co & Plain & $\begin{array}{c}\text { Cotton/ } \\
\text { polyester }\end{array}$ & $\begin{array}{c}\text { Cotton/ } \\
\text { polyester }\end{array}$ \\
\hline Co-Al & Plain & Nylon6 & Nylon6 \\
\hline Co-Cu & Plain & $\begin{array}{c}\text { Cotton/ } \\
\text { polyester }\end{array}$ & Copper \\
\hline $\mathrm{Ny}$ & Plain & $\begin{array}{c}\text { Cotton/ } \\
\text { polyester }\end{array}$ & Aluminium \\
\hline Ny-Al & Plain & Nylon6 & Copper \\
\hline Ny-Cu & Plain & Nylon6 & Aluminium \\
\hline
\end{tabular}

A weaving machine was used to produce the fabrics. During the fabric production, the aluminium and copper metallic yarns were inserted within the fabric structures as weft yarns. The woven fabrics structures comprised of different components and are illustrated in Figure 2.

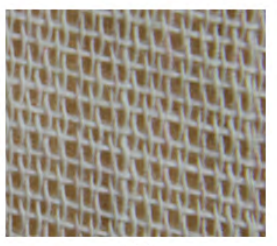

(A)

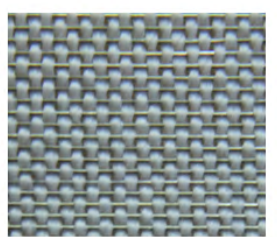

(D)

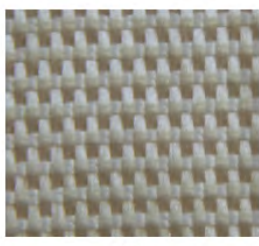

(B)

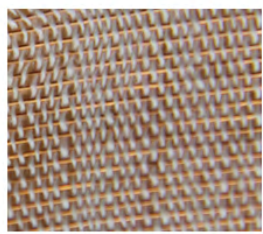

(E)

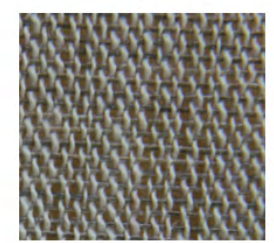

(C)

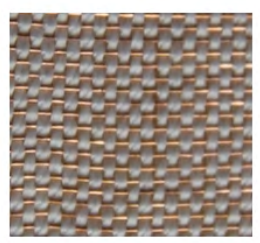

(F)
Figure 2. Fabric structures, (A) cotton/polyester fabric, (B) nylon fabric, (C) cotton/polyester fabric with aluminium weft yarns, (D) nylon fabric with aluminium weft yarns, $(E)$ cotton/polyester fabric with copper weft yarns, and $(F)$ nylon fabric with copper weft yarns

\subsection{Evaluation of textiles protection against the UV radiation}

UPF is an important quality index that represents the textile protection ability against the sun radiations. The higher UPF of a specific textile indicates its higher protection ability. UPF indeed expresses the time of exposure in which one individual can be stand under the sun radiation by wearing a protective textile without suffering from any sun related damages [2].

In order to calculate the UV protection factor (UPF) of textiles, which is known as fabric resistance ability against UV radiations, some quantitative experiments by using different measuring instruments are available [12]. The word UPF which is widely used in textile and clothing industries all over the world, indicate the protection ability of textiles based on the experimental measurements according to the standard AS/NZS 4399:1996Sun Protective Clothing-Evaluation and Classification. This factor could be calculated as the ratio of effective UV radiation mean value for an unprotected skin to the mean value of this radiation for the skin protected by a fabric or other coatings. In other words, according to the Equation 1 [17]:

$$
U P F=\frac{\sum_{290 m}^{400 m} E_{\lambda} S_{\lambda} \Delta \lambda}{\sum_{290 m}^{400 m} E_{\lambda} S_{\lambda} T_{\lambda} \Delta \lambda}
$$

where $E_{\lambda}$ is defined as the relative Erythermal spectral effectiveness (unitless), $S_{\lambda}$ is Solar UVR spectral irradiance $\left(\mathrm{Wm}^{-2} \mathrm{~nm}^{-1}\right), T_{\lambda}$ is the measured transitional spectrum of the fabric, $\lambda$ is wavelength $(\mathrm{nm})$ and $D_{\lambda}$ is the bandwidth $(\mathrm{nm})$.

After preparing the fabric samples according to the Table 4, their behaviour under the UV radiation exposure was evaluated. To perform the experiments, Jasco V-570 spectrometer apparatus and a Jasco ARN-475 connector were employed. Details of spectrometer characteristics are presented in Table 6.

Using specified software called Spectra Manager, the introduction to the spectroscopy can be defined for the system. In this research, the 1/52/01 version of the software programmed by Jasco company (2001) was used. The Spectra Manager software also can be employed for plotting the data resulting from the spectroscopy experiments. After performing the spectrophotometer, the values of spectrum for each sample were saved as a doc file in a Cartesian coordinate $\mathrm{XY}$. These saves doc files were used for plotting the spectroscopy curves for the samples as well as the mean value of their spectrum.

Table 6. The characteristics of Jasco V-570 spectrometer apparatus

\begin{tabular}{|c|c|}
\hline Wavelength rang & $190-2500 \mathrm{~nm}$ \\
\hline $\begin{array}{l}\text { Measurement } \\
\text { accuracy }\end{array}$ & $0.3 \mathrm{~nm}$ \\
\hline Type of the lamp & Tungsten - Deuterium \\
\hline Type of the detector & PbS Photocell - PMT \\
\hline Capability & $\begin{array}{c}\text { Relative / absolute reflection } \\
\text { measurement, Enzyme and } \\
\text { colour analysing, multicomponent } \\
\text { materials analysing }\end{array}$ \\
\hline
\end{tabular}

\section{RESULT AND DISCUSSION}

The spectroscopy for each fabric type was performed according to the procedure mentioned above. For each fabric types, four samples were tested and average curves were obtained. The average absorption curves in the case of cotton/PET and Nylon fabrics are shown in Figures 3 and 4. 
In order to calculate the UPF index of fabric samples, the standard values of SI, El and Tlare needed. The values of SI were determined based on ASTM G173-03 Reference Spectra (SMARTS v. 2.9.2). The values of El were determined based on erythema action spectrum (BS ISO 17166:1999). The values were determined between the ranges of 290 and $400 \mathrm{~nm}$ with the increment of one nanometre in each stage (DI=1). The amounts of the transmitted spectrum $\mathrm{TI}$ were also measured for all fabric types from spectroscopy data and average absorption cures in figures 3 and 4 in the range of
290-400 nm wavelength with an increment of one nanometre (DI=1). According to Equation (1), the protection factor can be determined; as in Equation (3) in the case of Cotton/PETAluminium fabric:

$$
U P F(C o-A l)=\frac{\sum_{290 \mathrm{~nm}}^{400 \mathrm{n} m} E_{\lambda} S_{\lambda} \Delta \lambda}{\sum_{290 \mathrm{~nm} m}^{400 \mathrm{~m} m} E_{\lambda} S_{\lambda} T_{\lambda} \Delta \lambda}=\frac{7.2}{2.5078}=2.8557
$$

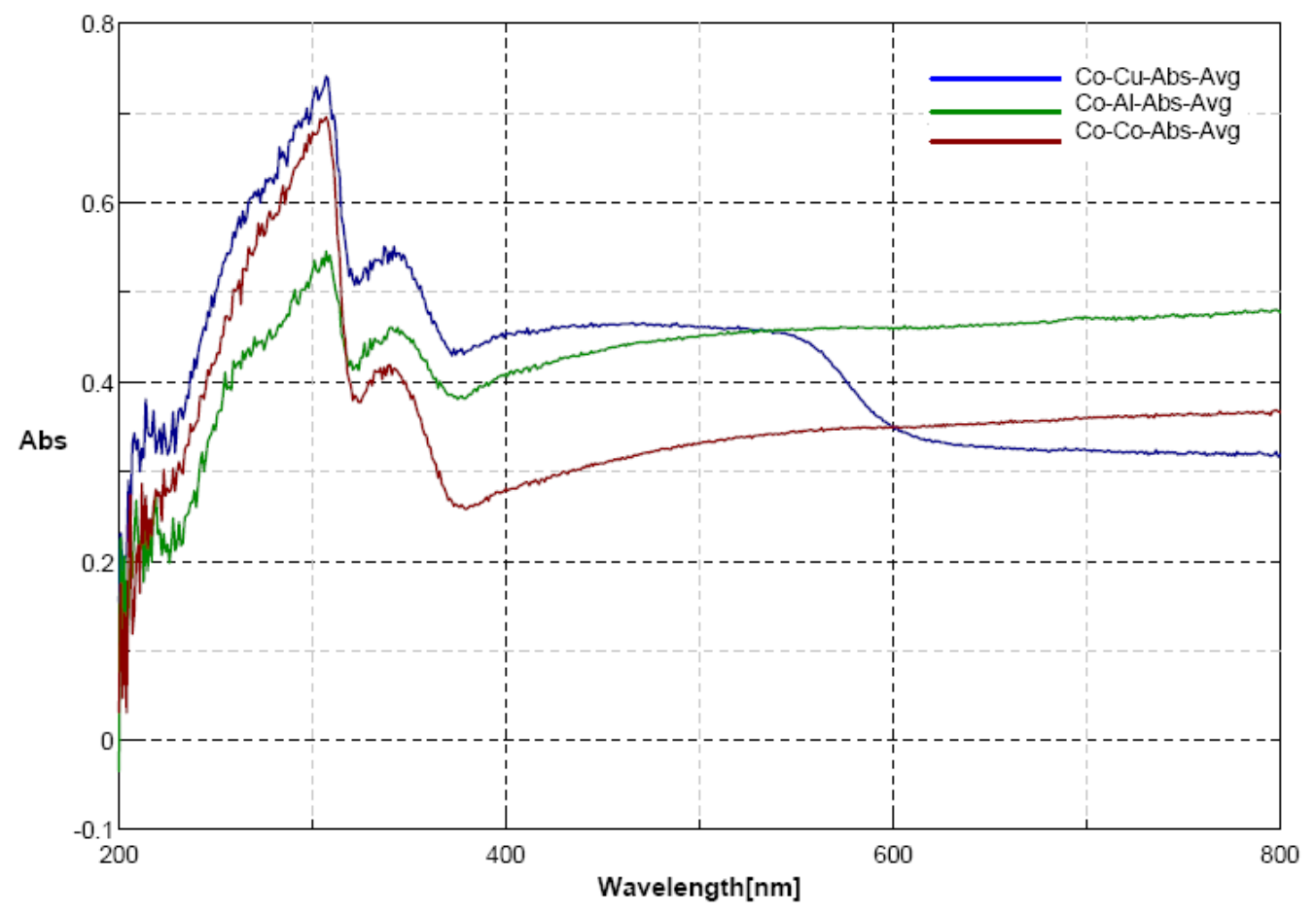

Figure 3. Average curves of abortion of cotton/PET fabrics

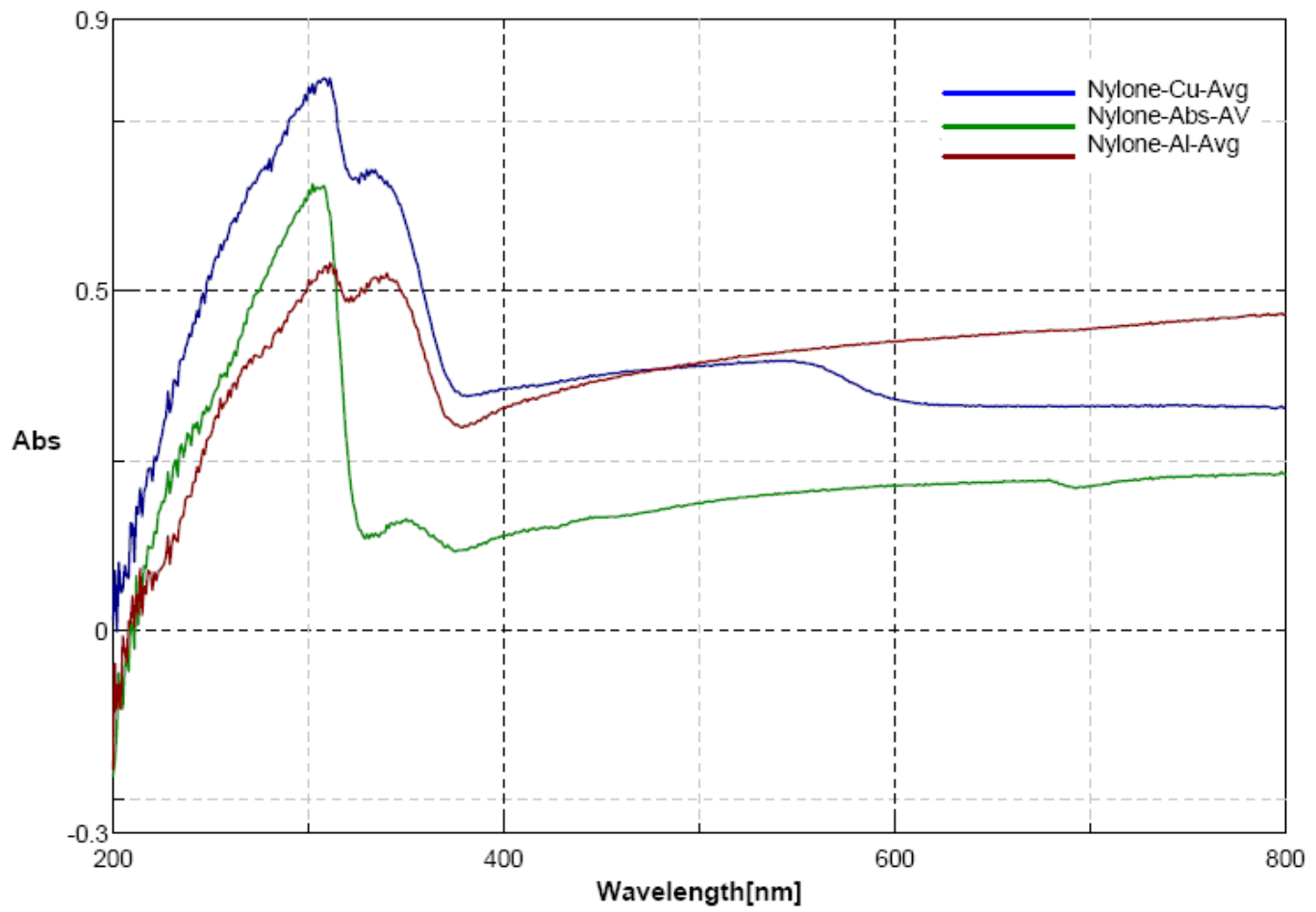

Figure 4. Average curves of abortion of Nylon fabrics 
Similarly, the amounts of the transmitted spectrum $\mathrm{TI}$ (with $\mathrm{DI}=1$ ) for other fabrics were measured at the wavelength ranged between 290 and $400 \mathrm{~nm}$ and their UPF indexes were calculated according to equation 1 .

The results of UPF indexes (protection factors) for all of the fabric samples prepared for this investigation are given in Table 7.

Table 7. UPF indexes of woven fabrics

\begin{tabular}{|c|c|c|}
\hline Fabric sample & Fabric type & $\begin{array}{c}\text { UPF } \\
\text { value }\end{array}$ \\
\hline Co & Cotton/Polyester & 4.3926 \\
\hline Co-Al & Cotton/polyester/Aluminium & 2.8557 \\
\hline Co-Cu & Cotton/Polyester/Copper & 4.4240 \\
\hline $\mathrm{Ny}$ & Nylon & 4.0883 \\
\hline $\mathrm{Ny}-\mathrm{Al}$ & Nylon/Aluminium & 3.1020 \\
\hline $\mathrm{Ny}-\mathrm{Cu}$ & Nylon/Copper & 5.9254 \\
\hline
\end{tabular}

The results illustrated that fabrics produced from copper yarns, exhibit the highest protection properties. This is also indicated by the absorption curves of the fabrics shown in Figures 3 and 4. In the range of $240-400 \mathrm{~nm}$, the absorption ratio of the fabrics composed of Copper weft yarns is higher than the aluminium composed fabric. To explain the reason, the emissivity coefficient of the materials must be considered. The emissivity coefficients of some materials are shown in Table 8. According to Table 8 , emissivity coefficient for aluminium, copper and cotton cloth is $0.05,0.78$ and 0.75 , respectively. Regarding an ideal black Body law, higher emissivity coefficient leads to more electromagnetic absorption and consequently enhances UV protection factor of fabric. With respect to higher Copper emissivity coefficient, the results of both Cotton-PET and Nylon 6 fabrics were supposed to indicate UPF improvement.

Table 8. Various Emissivity Coefficients

\begin{tabular}{|c|c|}
\hline $\begin{array}{c}\text { Emissivity } \\
\text { Coefficient }\end{array}$ & Materials \\
\hline 0.02 & Unoxidised Aluminium \\
\hline 0.11 & Oxidized Aluminium \\
\hline 0.31 & Heavily Oxidized \\
\hline 0.18 & Roughly Polished \\
\hline 0.09 & Aluminium Commercial Sheet \\
\hline 0.05 & Aluminium Alloy 1100 \\
\hline 0.93 & Asphalt \\
\hline 0.93 & Red brick \\
\hline $0.6-0.7$ & Copper electroplated \\
\hline 0.03 & Annealed Copper \\
\hline 0.78 & Copper Polished \\
\hline $0.023-0.052$ & Cotton Cloth \\
\hline 0.77 & Water \\
\hline $0.95-0.963$ & \\
\hline
\end{tabular}

Statistical analysis on the experimental results also confirmed that copper constructed fabrics show higher UPF in compression to Aluminium constructed fabrics. The Duncan statistical analysis results of cotton/polyester woven fabrics
UPF are given in Table 9. It can be seen that adding copper has increased the UPF of the fabric slightly. However, the differences are not statistically significant. The presence of aluminium in fabric structure leads to significant differences in decrement between the categories.

Table 9. Duncan test results of UPF for cotton/polyester woven fabrics

\begin{tabular}{|c|c|c|c|c|}
\hline \multicolumn{2}{|c|}{} & \multirow{2}{*}{ VAR00001 } & \multicolumn{2}{|c|}{$\begin{array}{c}\text { Subset for alpha } \\
=0.05\end{array}$} \\
\cline { 4 - 5 } & $\mathbf{1}$ & & $\mathbf{2}$ & \\
\hline \multirow{4}{*}{ Duncan $^{\mathrm{a}}$} & & & $\mathbf{2}$ & \\
\cline { 2 - 5 } & Cotton-Aluminium & 3 & 2.9060 & \\
\cline { 2 - 5 } & Cotton-Copper & 3 & & 4.4477 \\
\cline { 2 - 5 } & Cotton-Cotton & 3 & & 4.5154 \\
\cline { 2 - 5 } & Sig. & & 1.000 & .875 \\
\hline
\end{tabular}

According to the Table 10, the results of Duncan test for the samples show that the presence of aluminium in fabric structure has no significant effect while adding the copper component within the fabrics sample leads to differences in increment between the categories.

Table 10. Duncan test results of UPF for nylon woven fabrics

\begin{tabular}{|c|c|c|c|c|}
\hline \multicolumn{2}{|c|}{ VAR00001 } & \multirow{2}{*}{$\begin{array}{c}\text { N } \\
1\end{array}$} & \multicolumn{2}{c|}{$\begin{array}{c}\text { Subset for } \\
\text { alpha }=0.05\end{array}$} \\
\cline { 3 - 5 } & & $\mathbf{2}$ & \\
\hline \multirow{3}{*}{ Duncan $^{\mathrm{a}}{ }^{\mathrm{N}}$} & Nylon-Aluminium & 3 & 3.1340 & \\
\cline { 2 - 5 } & Nylon-Nylon & 3 & 4.2820 & \\
\cline { 2 - 5 } & Nylon-copper & 3 & & 5.9693 \\
\cline { 2 - 5 } & Sig. & & 0.066 & 1.000 \\
\hline
\end{tabular}

\section{CONCLUSIONS}

From the UPF results obtained for different woven fabrics, it was observed that for those fabrics containing the copper yarns, the higher UPF value was achieved in comparison to fabrics containing the aluminium yarns. The emission-ability coefficients for aluminium, copper, and cotton fabric are 0.05 , 0.78 and 0.75 , respectively. Considering the laws of an ideal black object, the higher emission-ability coefficient of a textile material leads to an increase in the possibility of electromagnetic wave absorption. The copper, due to its high emission-ability coefficient, is able to absorb much more electromagnetic waves. As a result, the possibility of light transmission through the copper fabric would be decreased and so these structures could be considered as an acceptable alternative for other commonly used protective textiles.

\section{ACKNOWLEDGEMENT}

The authors would like to express their sincere thanks to the deputy of research of Isfahan University of Technology for the financial support. 


\section{REFERENCES}

[1] Hilfiker, R., Kaufmann, W., Reinert, G., (1996), Schmidt, E., Improving Sun Protection Factors of Fabrics by Applying UV-Absorbers, Textile Research Journal, 66(2), 61-70.

[2] Scott, R.A. (2005), "Textile for Protection", Woodhead Publishing Limited in association with The Textile Institute, England.

[3] Butola, B.S., Joshi M., (2013), Photo stability of HDPE filaments stabilized with UV absorbers (UVA) and light stabilizers (HALS), J. Eng. Fibers Fabrics, 8(1), 61-68.

[4] Chowdhury, M.A., Joshi, M., Butola, B.S., (2014), Photochromic and Thermochromic Colorants in Textile Applications, J. Eng. Fibers Fabrics, 9(1), 107-123.

[5] Edlich, R.F., Cox, M.J., Becker, D.G., Horowitz, J.H., Nichter, L.S., Britt, L.D., Edlich, T.J., Long, W.B., (2004), Revolutionary Advances in Sun Protective Clothing - An Essential Step in Eliminating Skin Cancer in Our World, J. of Long Term Effects of Medical Implants, 14(2), 5-105.

[6] Alvarez, J., Symonowicz, B.L., (2003), Examination of the Absorption Properties of Various Fibres in Relation to UV Radiation, AUTEX Res. J. 3(2), 72-77.

[7] Gupta, D., Jain, A., Panwar, S., (2005), Anti UV and Antimicrobial Properties of Some Natural Dyes on Cotton, Indian Journal of Fibre and Textile Research, 30(2), 190 195.

[8] Bajaj, P., Kothari, V.K., Ghosh, S.B., (2000), Some Innovations in UV Protective Clothing, Indian J. of Fibres and Textile Research, 35(4),315-329.

[9] Saravanan, D., (2007), UV protection textile materials, AUTEX Res. J., 7(1), 53-62.

[10] Farouk, A., Textor, T., Schollmeyer, E., Tarbuk, A., Grancacic, A.M., (2010), Sol-gel-derived inorganicorganic hybrid polymers filled with $\mathrm{ZnO}$ nanoparticles as an ultraviolet protection finish for textiles, AUTEX Res. J., 10(3), 58-63.
[11] Wilson, C.A., Parisi, A.V., (2006), Protection from Solar Erythemal Ultraviolet Radiation - Simulated Wear and Laboratory Testing, Textile research Journal, 76(3), 216225.

[12] Gambichler, T., Avermaete, A., Bader, A., Altmeyer, P., Hoffman, K., (2001), Ultraviolet protection by summer textiles, Ultraviolet transmission measurements verified by determination of the minimal erythemal dose with solarsimulated radiation, British Journal of Dermatology, 144, 484-489.

[13] Curiskis, J., Pailthorpe, M., (1996), Apparel Textiles and sun protection, Textiles Magazine, 25(4), 13-17.

[14] Algaba, I., Riva, A., Crews, P.C., (2004), Influence of fiber type and fabric porosity on the UPF of summer fabrics. AATCC Review, 4(2), 26-31.

[15] Crews, P.C., Kachman, S., Beyer, A.G., (1999), Influences on UVR transmission of undyed woven fabrics, Textile Chemist and Colorist, 31(6), 17-26.

[16] Dubrovski, P.D., Golob, D., (2009), Effects of Woven Fabric Construction and Color on Ultraviolet Protection, Textile Research Journal, 79(4), 351-359.

[17] Fact Sheet, Radiation Measurement (2003) Department of Health and Human Services, CDC Radiation Emergencies. (On-line) Available: http://www.bt.cdc.gov/radiation/pdf/ measurement.pdf. Cited 2008 Dec 22.

[18] Serway, R.A., Moses, C.J., Moyer, C.A., (2005), Modern Physics, 3rd edition, Thomson, United States of America.

[19] Bevelacqua, J.J., (2009), Contemporary Health Physics, 2nd edition, Wiley-VCH, 2009.

[20] Gies, P.H., Roy, C.R., Holmes, G., (2000), Ultraviolet Radiation Protection by Clothing: Comparison of In vivo and In vitro Measurements, Radiation protection Dosimetry, 91(1-3), 247-250.

[21] Dimitrovski, K., Sluga, F., Urbas, R., (2010), Evaluation of the Structure of Monofilament PET Woven Fabrics and their UV Protection Properties, Textile Research Journal, 80(11), 1027-1037. 